\title{
The Effect of Acute Hyperglycaemia on the Retinal Circulation of the Normal Cat
}

\author{
Anne Atherton, D. W. Hill, H. Keen, S. Young, and E. J. Edwards \\ Research Department of Ophthalmology, Royal College of Surgeons, Lincoln's Inn Fields, and Unit for Metabolic Medicine, \\ Guy's Hospital Medical School, London Bridge, London, England
}

\begin{abstract}
Summary. The retinal microcirculation of anaesthetised normal cats was studied during hyperglycaemia ( 15 to $55 \mathrm{mmol} / \mathrm{l}$ ) induced by intravenous infusion of glucose, using high speed cine fluorescence angiography. Saline $(0.150 \mathrm{mmol} / \mathrm{l})$ was infused as a control for the volume effect of glucose solution and equiosmolar mannitol was infused as a control for the osmotic effect. The mean retinal arteriolar inflow rate increased from $34 \pm 1 \mathrm{~mm} / \mathrm{sec}$ to $41 \pm 4 \mathrm{~mm} / \mathrm{sec}$ during glucose infusion, and from $46 \pm 1 \mathrm{~mm} / \mathrm{sec}$ to $56 \pm 3 \mathrm{~mm} / \mathrm{sec}$ during mannitol infusion. The blood pressure similarly increased from $105 \pm 5 \mathrm{mmHg}$ to $125 \pm 2 \mathrm{mmHg}$ during glucose infusion and from 110 $\pm 7 \mathrm{mmHg}$ to $129 \pm 1 \mathrm{mmHg}$ during mannitol infusion. During mannitol infusion the increased inflow was accompanied by a reduction in the arteriolar width so that the volume flow remained unchanged. During glucose infusion this constriction did not occur, resulting in a significantly increased volume of retinal blood flow $(9 \pm 1 \mu \mathrm{l} / \mathrm{min}$ to $12 \pm 1 \mu \mathrm{l} / \mathrm{min})$.
\end{abstract}

Key words: Diabetic retinopathy, glucose, vessel calibre, fluorescence angiography, autoregulation, cats.

Although there is indirect evidence in man of a correlation between the severity of diabetic retinopathy and the degree of metabolic disturbance [1], there is little indication as to which, if any, of the biochemical disturbances might be responsible. An elevated and fluctuating blood glucose is common to all diabetic syndromes and raises the possibility that hyperglycaemia itself may have an effect on retinal vascular function. In the present study we have thus investi- gated the effect of acute short-term hyperglycaemia induced by intravenous infusion on retinal perfusion in the normal cat, using high speed cine fluorescence angiography to measure arteriolar inflow and vessel calibre [2]. This technique allows repeated estimations of blood flow during the course of an experiment with an accuracy adequate to register confidence limits varying between approximately $5-15 \%$ of the mean [2].

\section{Materials and Methods}

The techniques of cat selection and preparation were as previously described in detail by Hill and Young [2] with some modifications. Healthy domestic cats of either sex weighing between 2.5 and $5.0 \mathrm{~kg}$ were anaesthetised with intravenous sodium pentobarbitone $(30 \mathrm{mg} / \mathrm{kg})$ following an intramuscular injection of chlorpromazine $(2 \mathrm{mg} / \mathrm{kg})$ given $45 \mathrm{~min}$ previously as a premedication. Anaesthesia was maintained by continuous IV infusion of sodium pentobarbitone, $9 \mathrm{mg} / \mathrm{kg} / \mathrm{h}$. After trachteostomy, respiration of mixed gases $\left(70 \% \mathrm{~N}_{2}, 30 \% \mathrm{O}_{2}\right)$ was maintained with a Palmer 'Ideal' pump operating at 37 strokes/min with a stroke volume of $9 \mathrm{ml} / \mathrm{kg}$ body weight. Blood pressure was monitored continuously using a blood pressure transducer connected to a cannula in one femoral artery and thence to a multichannel recorder. Rectal temperature was similarly monitored continuously using a rectal thermocouple. Blood gases were analysed every 15 minutes from a $0.5 \mathrm{ml}$ arterial blood sample using a Technicon blood gas analyser. Deviations of these from normal were promptly corrected by appropriate compensations in management. Blood pressure changes provided an index of the degree of anaesthesia or indicated large fluid losses - these could be compensated for. If blood gases were not adequately normalized and fluctuated markedly despite preventative measures the experiment was terminated. Arterial blood samples were taken at frequent intervals for blood glucose estimation using an Analox Instruments Glucose Analyser.

Each angiogram was obtained by the injection of a $40 \mu \mathrm{l}$ bolus of $5 \%$ fluorescein delivered to the carotid artery via a cannula placed in the ipsilateral lingual artery [2]. The injector was electromagnetically triggered to the run-up of the camera. High speed cine angiography of the retina was performed at $141 \mathrm{fps}$ using a 


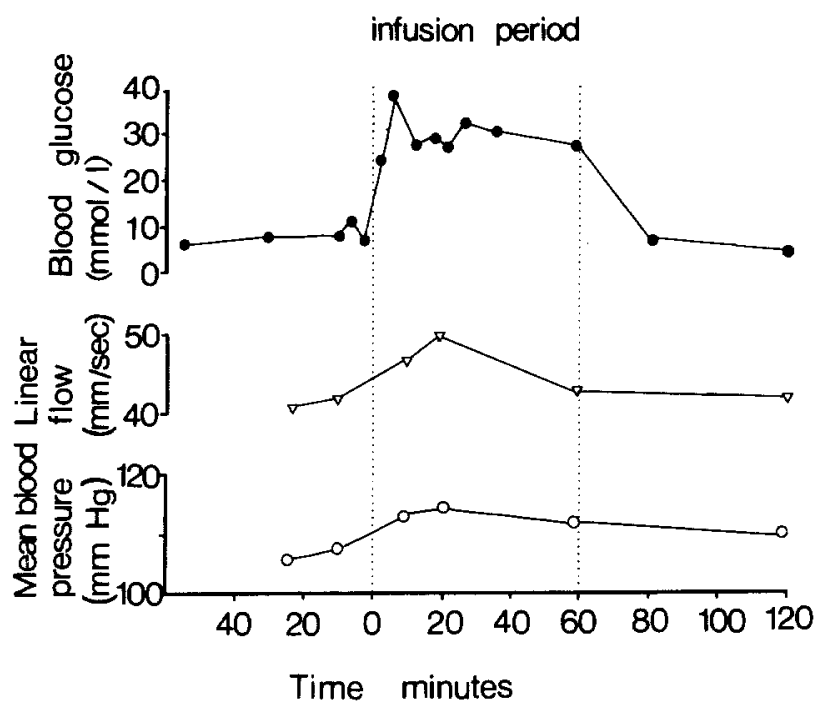

Fig. 1. The changes in blood glucose values, systemic blood pressure, and mean linear flow rate for six vessels in the retina, occurring in one cat during an intravenous infusion of glucose. For details see text

Table 1. Blood glucose concentration (mmol/l)

\begin{tabular}{lllllll}
\hline $\begin{array}{l}\text { Saline } \\
\begin{array}{l}\text { Before } \\
\text { infusion }\end{array}\end{array}$ & $\begin{array}{l}\text { During } \\
\text { infusion }\end{array}$ & $\begin{array}{l}\text { Glucose } \\
\text { Before } \\
\text { infusion }\end{array}$ & $\begin{array}{l}\text { During } \\
\text { infusion }\end{array}$ & $\begin{array}{l}\text { Mannitol } \\
\text { Before } \\
\text { infusion }\end{array}$ & $\begin{array}{l}\text { During } \\
\text { infusion }\end{array}$ \\
\hline $8.3 \pm 0.4$ & $8.5 \pm 0.2$ & $8.6 \pm 1.2$ & $38.2 \pm 8.3$ & $6.6 \pm 0.1$ & $6.3 \pm 0.2$ \\
$5.9 \pm 0.2$ & $6.4 \pm 0.1$ & $7.5 \pm 0.2$ & $28.4 \pm 5.5$ & $7.5 \pm 0.4$ & $7.7 \pm 0.3$ \\
$9.2 \pm 0.4$ & $7.1 \pm 0.7$ & $5.3 \pm 0.2$ & $29.3 \pm 3.9$ & $5.2 \pm 0.1$ & $5.2 \pm 0.4$ \\
$9.5 \pm 0.1$ & $9.3 \pm 0.7^{\mathrm{a}}$ & $3.7 \pm 0.3$ & $16.7 \pm 2.2^{\mathrm{a}}$ & $8.0 \pm 0.4$ & $7.7 \pm 0.7^{\mathrm{a}}$ \\
$6.1 \pm 0.2$ & $6.7 \pm 0.4$ & $9.7 \pm 0.2$ & $25.7 \pm 2.8$ & $7.5 \pm 0.2$ & $7.6 \pm 0.4^{\mathrm{a}}$
\end{tabular}

Mean blood glucose values \pm SEM in each of 15 cats before and during the intravenous infusion of either saline, glucose or mannitol as described in the text. The retinal blood flow values from the cats marked ${ }^{a}$ were not included in the results due to technical difficulties with the angiography

modified West German Zeiss fundus camera. The details of this procedure have been described in detail [3].

Hyperglycaemia was achieved by an intravenous infusion of glucose in $0.150 \mathrm{~mol} / \mathrm{l}$ saline. During a preliminary baseline control period, when the physiological state had stabilised adequately following surgery, two 'blocks' each consisting of six angiograms over a period of $1-2 \mathrm{~min}$ were taken, $30 \mathrm{~min}$ and $15 \mathrm{~min}$ before the time at which the infusion was scheduled to start. In 5 experiments intravenous infusion of a solution containing 5.6 moles of glucose/ $\mathrm{kg}$ body weight in a total volume of $10 \mathrm{mls}$ saline was commenced at a rate of $2 \mathrm{ml} / \mathrm{min}$ for $5 \mathrm{~min}$ and was continued $(0.56 \mathrm{~mol} / \mathrm{kg}$ in a volume of $27.5 \mathrm{ml}$ ) at a rate of $0.5 \mathrm{ml} / \mathrm{min}$ for a further $55 \mathrm{~min}$.

In another 5 experiments saline $(0.150 \mathrm{~mol} / \mathrm{l})$ was infused at the same rate as a control for volume effect. Mannitol was infused in a further 4 experiments as a solution containing 5.6 moles of mannitol $/ \mathrm{kg}$ body weight in $10 \mathrm{mls}$ saline, as a control for the osmotic effect of the infused glucose. Two further blocks of angiograms were taken 10 and 20 min after the start of infusion, and a third block at the end of the infusion period. This was fol- lowed by a recovery period lasting $60 \mathrm{~min}$ after which one further angiogram block was taken.

The angiograms obtained were analysed for two parameters:

1) Vessel calibre at maximum filling, using a low power microscope with a screw micrometer, at prefixed points defined by the vascular anatomy.

2) Linear flow velocity in the arterioles determined by analysing the number of frames elapsing whilst the bolus tip passed between two selected points.

An estimation of relative volume flow can be derived from these two parameters, since the volume flow is a function of the cross-sectional area and the linear velocity. Between three and six arterioles in each retina were selected for analysis, the choice depending mainly on absence of filling defects, vessels without side branches long enough to make accurate measurements, and the fact that some arterioles were obscured by venules running alongside. For each vessel the changes of calibre and flow were expressed logarithmically (logarithmic change, LC) as a proportion of the baseline control values.

Logarithmic expression of proportions gives an equal numerical weight to increases and decreases and simplified statistical handling of the data. Estimates of mean logarithmic change (MLC) were derived for all vessels during a single angiogram block. These figures were subjected to statistical analysis using a two-way Analysis of Variance test for fluctuations within the angiogram blocks, and a paired ' $t$ ' test for comparison between blocks and animals.

\section{Measurement of Vessel Calibre Using $35 \mathrm{~mm}$ Photography}

As a further check on the reproducibility of calibre measurements made using $16 \mathrm{~mm}$ frames, a set of supplementary experiments was devised specifically to measure vessel calibres with greater accuracy. Photographs of the retina were taken on $35 \mathrm{~mm}$ film at $0.3 \mathrm{sec}$ intervals during the passage of the fluorescein with a motorised Nikon camera back and analysed for vessel width using a scanning micro-densitometer as described by Griffiths et al. [4]. All other techniques were unchanged.

\section{Results}

The blood glucose was elevated by infusion to levels which remained relatively constant in individual cats, at plateau varying between approximately 15 and $55 \mathrm{mmol} / 1$ (mean $28.5 \mathrm{mmol} / 1$ ). The increase to maximum level was rapid, usually within 5 minutes of commencing infusion. Discontinuing the infusion resulted in a rapid fall to near pre-infusion levels. Figure 1 shows a typical blood glucose curve under these conditions. The mean blood glucose values during the baseline control period, and during the 60 minutes following the commencement of infusion of either saline, glucose, or mannitol are shown in Table 1.

\section{Linear Flow Rate}

The linear flow rate in retinal arterioles was increased by about $20 \%$ during the period of glucose 
infusion in all cats tested. Figure 1 shows a representative increase as it occurred in a single cat. The proportional change in flow rate expressed logarithmically was statistically significantly increased over the baseline control values, both in single vessels and the selected group of vessels under observation. The linear flow rate was elevated immediately following the induction of hyperglycaemia and fell to near normal levels in parallel with blood glucose concentrations. Infusion of the same volume of saline was without significant effect. However, mannitol infused at the same osmolar concentration caused a rise in linear flow rate, initially of similar extent to that caused by glucose although possibly decreasing more quickly. Figure 2 shows the pooled mean logarithmic changes (MLC's) in linear flow rate for all cats during glucose, saline and mannitol infusion.

\section{Calibre}

Measurements of vessel widths from the 16 and $35 \mathrm{~mm}$ films showed no significant change in vessel width from baseline control values during glucose infusion. Saline also failed to produce a significant calibre change; however in response to mannitol infusion, a significant diminution in arteriolar calibre was observed (Fig. 3).

\section{Volume Flow}

The volume of blood passing through the retinal vessels was estimated from the observed values for linear flow rate and calibre. During the period of hyperglycaemia induced by glucose infusion, there was significant increase in the estimated volume flow through the retinal arterioles. The increased linear flow occurring when mannitol was infused was counterbalanced by diminished arteriolar calibre resulting in estimated volume flow not differing significantly from baseline (Fig. 4).

\section{Systemic Blood Pressure and Volume}

The mean systemic blood pressure (diastolic pressure $+1 / 3$ pulse pressure) was increased during glucose and mannitol infusion by about $20 \%$, whereas saline produced no change. In both the former cases the rise occurred within 5 minutes of commencing infusion, but with the glucose infusion the blood pressure remained significantly increased for longer than with mannitol. Figure 1 shows the blood pressure increase in a single cat, and Figure 5 demonstrates the pooled logarithmic changes in blood pressure for saline, glucose and mannitol infusion. After the infusion stopped blood pressure fell to control levels within 15-20 min.

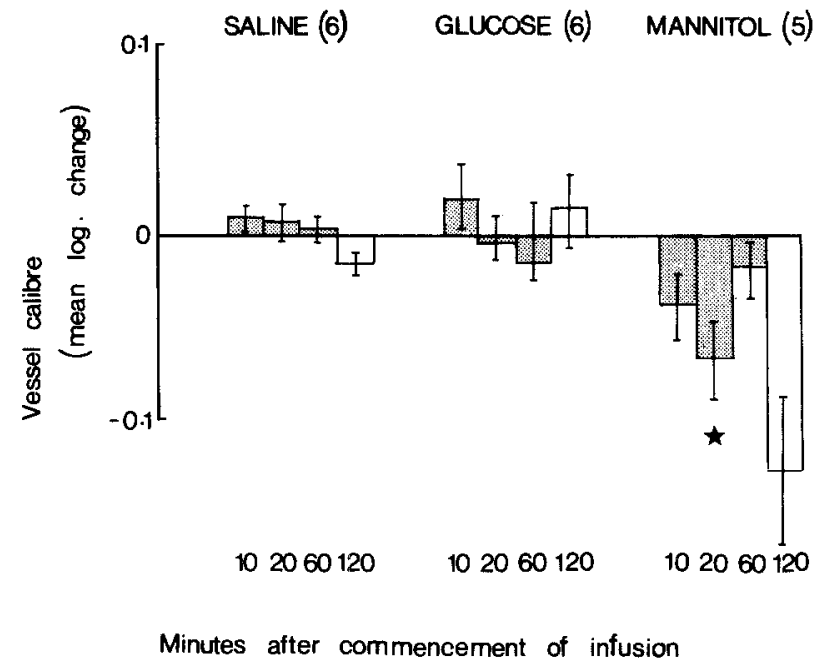

Fig. 3. The changes in mean vessel calibre \pm SEM (expressed logarithmically and using pooled data from the number of cats stated in parentheses), in normal cats receiving an intravenous infusion of saline, glucose or mannitol. The shaded blocks represent values at 10,20 and 60 minutes after infusion; the unshaded histogram blocks represent values determined 60 minutes after the infusion had been discontinued. The absolute values in the three groups of cats for mean vessel calibre in retinal arterioles during the baseline control period are: saline $72.6 \pm 3.4 \mu$, glucose $68.4 \pm$ $2.9 \mu$, and mannitol $70.5 \pm 3.8 \mu$. The vessel calibres during the experimental period are compared to those during the baseline control period (* $=p<0,05$ ) (paired 't' test) 


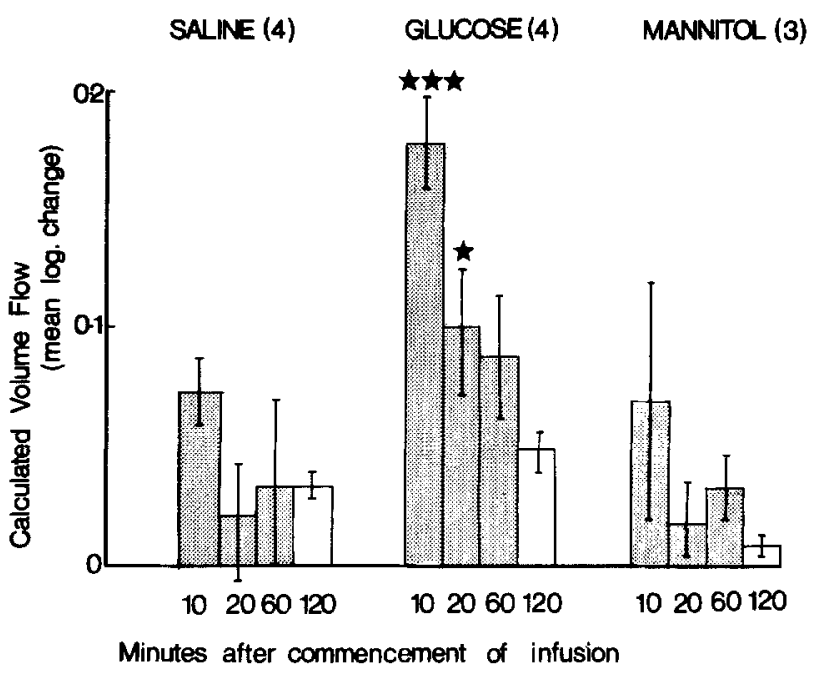

Fig. 4. The changes in mean volume flow \pm SEM (expressed logarithmically and using pooled data from the number of cats stated), in normal cats receiving an intravenous infusion of saline, glucose or mannitol. The shaded blocks represent values at 10,20 and 60 minutes after infusion; the unshaded blocks represent values determined 60 minutes after the infusion had been discontinued. The absolute values in the three groups of cats for the volume flow in retinal arterioles during the baseline control period are: saline $14.0 \pm 0.9 \mu \mathrm{l} / \mathrm{min}$, glucose $9.34 \pm 0.5 \mu \mathrm{l} / \mathrm{min}$, mannitol $13.8 \pm 4.9 \mu \mathrm{l} / \mathrm{min}$. The volume flows during the experimental period are compared to those during the baseline control period (* $=\mathrm{p}<0.05$, **** $\mathrm{p}=<0.01$ ) (paired ' $\mathrm{t}$ ' test)

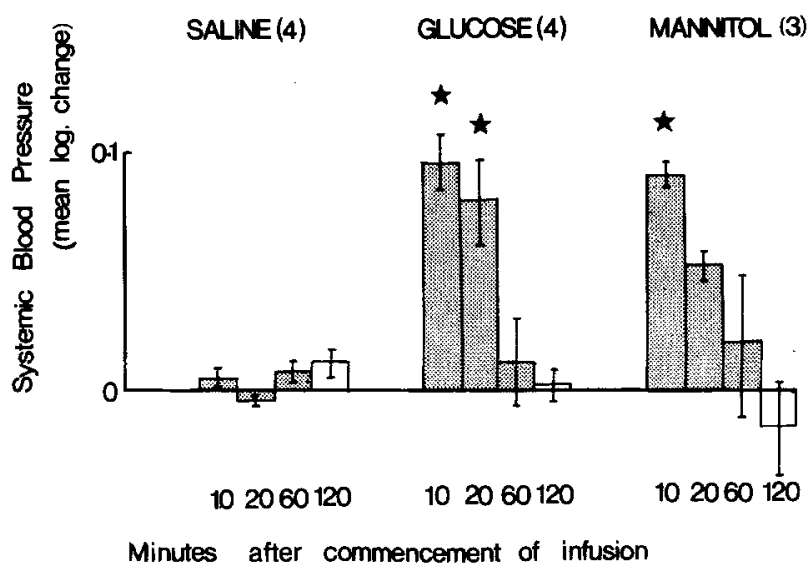

Fig. 5. The changes in mean systemic blood pressure $\pm S E M$ (expressed logarithmically using pooled data from the number of cats in parentheses) in normal cats receiving an intravenous infusion of saline, glucose or mannitol. The shaded blocks represent values at 10,20 and 60 minutes after infusion; the unshaded represent values determined 60 minutes after the infusion had been discontinued. The absolute values in the three groups of cats for mean systemic blood pressure during the baseline control period are: saline $107.1 \pm 5.1 \mathrm{mmHg}$, glucose $105.0 \pm 4.5 \mathrm{mmHg}$, mannitol $110.3 \pm 7.3 \mathrm{mmHg}$. The blood pressures during the experimental period are compared to those during the baseline control period $(*=p<0.05)$ (paired ' $\mathrm{t}$ ' test)

\section{Discussion}

The data from angiograms taken during saline, glucose and mannitol infusion in normal cats strongly suggests that induced hyperglycaemia is associated with significant changes in the pattern of retinal blood flow. The rate of linear inflow was increased, and in the absence of accompanying constriction of the arterioles, the estimated volume flow rose. This change occurred by the first point of measurement, $10 \mathrm{~min}$ after commencing hyperglycaemia, and continued until the blood glucose level returned to normal. The period of hyperglycaemia has so far been restricted to $60 \mathrm{~min}$ and it is possible that the flow increase occurs only as an initial response to the acute rise in blood glucose and would eventually normalize if hyperglycaemia continued. The effect of duration of hyperglycaemia and the rate of its induction are currently being investigated. The concentrations of blood glucose used were high but within the range observed in poorly controlled diabetes in man.

The increased linear flow rate may be due to the increased perfusion pressure in the retinal arteries resulting from the systemic blood pressure rise although other explanations such as reduced cup resistance or altered blood viscosity are possible. This in its turn may be induced by an increased blood volume resulting from the osmotic action of glucose. Mannitol, used to control for osmotic effect, produced the same initial rise in linear flow rate, although it was of shorter duration and falling despite a progressive rise in the plasma concentration of the non-metabolisable hexitol.

The difference between the retinovascular response to glucose and mannitol infusion was striking and consistent and suggests a breakdown in the normal processes of tissue autoregulation in the case of glucose. Autoregulation may be defined as the tendency of an organ to maintain constant blood flow by alterations in the vessel calibres despite changes in the arterial perfusion pressure [5]. Autoregulation in the retina has been shown to occur under increased blood pressure [6]. ffytche et al. [7] have demonstrated that when retinal perfusion pressure is decreased by mechanical methods, the volume flow is maintained at approximately constant levels by compensatory arteriolar calibre changes. This autoregulation appears to operate with the mannitol-induced increase in perfusion pressure but not when it results from induced hyperglycaemia. Unlike mannitol, glucose is rapidly metabolised by retinal tissue and it is possible that high local concentrations of metabolites may have vasomotor effects which override the nor$\mathrm{mal}$ autoregulatory mechanisms. Indeed it has been suggested that tissue metabolites may play an impor- 
tant part in maintaining the local constancy of oxygen supply.

The special vulnerability of the non-insulin sensitive retina [8] to hyperglycaemia may be related to its very high glucose consumption which increases linearly with ambient glucose concentration [8]. Metabolism of glucose in the retina is predominantly glycolytic, and the increase in glucose consumption induced by hyperglycaemia would be expected to generate high local concentrations of pyruvate, lactate, and other metabolites, perhaps producing a spurious anoxic signal. High retinal tissue lactate concentrations were found by Keen and Chlouverakis [8] in rats rendered hyperglycaemic by various means, and these findings have been confirmed by others [9].

Elevation of blood glucose concentration has several prompt consequences, including hormone release from pancreatic islet $B$ cells, inhibition of growth hormone release, and probably stimulation of vasopressin release. Such associated changes may contribute to or be responsible for the circulatory phenomena observed. The insulin response to intravenous glucose may itself affect vascular tone. Page and Watkins [12] described a hypotensive response to injected insulin in diabetics with autonomic neuropathy which could not be accounted for by a fall in plasma volume, demonstrable in diabetics without neuropathy, and in nondiabetics [13]. The possible direct effect of the hormone might be by way of insulin diminution of vascular nor-adrenaline responsiveness [14]. However, the plasma insulin concentrations generated by intravenous insulin boluses are very high.

Kohner et al. [15] have presented evidence suggesting that increased retinal blood flow is a feature of early diabetes, and can be observed before any of the gross pathological changes take place. The presence of microcirculatory responses to glucose in the retina of man, comparable to those in the cat, has yet to be demonstrated, and their importance evaluated in relation to the evolution of diabetic retinopathy.

\section{References}

1. Tchobroutsky G (1978) Relation of diabetic control to development of microvascular complications. Diabetologia 15: 143-152

2. Hill DW, Young S (1976) Arterial inflow studies of the cat retina using high speed cine angiography. Exp Eye Res 23: $35-45$

3. Young S (1975) High speed cine angiography. Medical and Biol Illustration 24: 199-204

4. Griffiths JD, Hill D W, Young S (1974) Measurement of apparent vessel width fluorescence angiography of the fundus oculi. Ophthalmol Res 6: 1-5

5. Tsacopoulos M (1977) The regulation of retinal blood flow. In: Hill DW, Perkins ES (eds) Scientific Foundations of Opthalmology. Heinemann, London, p 45-49

6. Hickam J, Frayser R (1966) Studies of the retinal circulation in man: Observations on vessel diameter, arteriovenous oxygen difference, and mean circulation time. Circulation 33: 302

7. ffytche TJ, Bulpitt CJ, Kohner EM, Archer D, Dollery CT (1974) Effect of changes in intraocular pressure on the retinal microcirculation. Br J Ophthalmol 58: 514-522

8. Keen H, Chlouverakis C (1965) Metabolic factors in diabetic retinopathy. In: Graymore $\mathrm{CN}$ (ed) Biochemistry of the retina. Academic Press, London New York

9. Heath H, Kang S S, Philippou D (1975) Glucose, glucose - 6 phosphate, lactate and pyruvate content of the retina, blood and liver of streptozotocin - diabetic rats fed sucrose - or start-rich diets. Diabetologia 11: 57-62

10. Page MMcB, Watkins PJ (1976) Provocation of postural hypotension by insulin in diabetic autonomic neuropathy. Diabetes 25: 90-95

11. Mackay JD, Hayakawa H, Watkins P H (1978) Cardiovascular effects of insulin: plasma volume changes in diabetics. Diabetologia 15: 453-457

12. Alexander WD, Oake RJ (1977) The effect of insulin on vascular reactivity to nor-adrenaline. Diabetes $26: 611-614$

13. Kohner EM (1976) Problems of retinal blood flow in diabetes. Diabetes 25 [Suppl 2]: 839-844

Received: August 14, 1979 ,

and in revised form: October 19, 1979

Dr. Anne Atherton

Research Department of Ophthalmology

Royal College of Surgeons

Lincoln's Inn Fields

London WC 2

England 